\title{
Lugares de Fala: um conceito para abordar o segmento popular da grande imprensa
}

Márcia Franz Amaral

\begin{abstract}
Resumo
O artigo apresenta o conceito de Lugar de Fala como instrumento teóricometodológico para delinear especificidades a serem consideradas na análise do segmento popular da grande imprensa. Parte da noção de que os jornais se transfiguram para falar a diferentes leitores por motivos tanto mercadológicos como comunicacionais. Os jornais de referência e os ligados ao segmento popular falam de lugares diferentes, concedem espaços variáveis às vozes oficiais e populares em suas páginas e seus discursos são aceitos em lugares diversos. Com o conceito de Lugar de Fala, demonstramos a importância de o jornalismo ser pensado e analisado em consonância com o mercado simbólico para o qual é produzido, o que não significa aceitar sua subordinação ao mercado, mas sim compreender sua conexão com o mundo popular.
\end{abstract}

Palavras-chave: Jornalismo, sensacionalismo, Lugar de Fala.

\begin{abstract}
The article presents the concept of place of speech as instrument theoreticatmethodological to delineate specificities to be considered in the analysis of the popular segment of the great press. It starts from the notion that the newspapers transfigure themselves to talk to different readers for both marketing and communication reasons. The reference and the linket to popular segment newspapers talk from different places, grant variable spaces 10 the official and popular voices on their pages and their discourses are accepted in diverse places. With the concept of place of speech, we demonstrute the importance of the journalism being thought and analyzed in accord with the symbolic market for which it is produced and it does not mean to accept its subordination to the market, but to understand its connection with the popular world.
\end{abstract}

Key words: Journalism, sensationalism, place of speech.

\footnotetext{
- Professora do curso de Comunicação Social da Universidade Federal de Santa Maria e doutora pelo Programa de Pós- Graduação em Ciências da Comunicação e Informacaao da Universidade Federal do Rio Grande do Sul. Endereço eletrónico: marciafamaral@uol.com.br
} 


\section{Introdução}

O conceito de Lugares de Fala foi construído na tese de doutorado Lugares de Fala do leitor no Diário Gaúcho para analisar um jornal popular da grañde imprensa cujas estratégias de popularização não se reduzem ao sensacionalismo. A intenção desse artigo é descolar esse conceito de um objeto empírico determinado e transformá-lo em uma categoria de análise mais ampla.

O conceito foi sistematizado porque o Diário Gaúcho $(D G)$, editado pela Rede Brasil Sul no RS, com mais de um milhão de leitores, segue uma tendência constatada em diversos países, de publicações que vendem exemplares avulsos, têm preços muito baixos, são editadas em pouças páginas, destinam publicidades ao grande público, dependem da estrutura de uma 'editora mãe'e não apostam em sexó e escândalos, como afirmá Giner (2004) (entre eles estão: El Comercio e Correo no Peru, La Nación na Costa Rica, Al Dia e Nuestro Diário na Guatemala, Super Express na Polônia, Correio da Manhã em Portugal).

As especificidades do $D G$ fizeram com que elaborássemos um aporte teórico que desse conta de explicar o contexto do sucesso de tais publicações, sem que nos circunscrevêssemos ao conceito de sensacionalismo.

\section{Sensacionalismo e Lugar de Fala}

O conceito de Lugares de Fala surge na tentativa de abordar questões que a noção de sensacionalismo não responde, pois por intermédio dela, normalmente, a imprensa popular é analisada do ponto de vista dos valores que regem a imprenșa de referência e o que não corresponde a eles costuma ser rotulado de estratégia mercadológica. Conseqüentemente, os jornais populares são muito criticados, mas pouco explicados. No lugar do sensacionalismo, rótulo que nos indica a intensidade de sensações geradas por estratégias como invenções, exageros, distorções e omissões, o Lugar de Fala busca explicar por que a imprensa dirigida a esse público opera com Modos de Endereçamento distintos dos usados na imprensa de referência e constrói sua credibilidade de outras maneiras. Do nosso ponto de vista, o lugar de onde fala o segmento popular da grande imprensa é diferente do lugar do segmento de referência. A imprensa popular, ao dirigir-se a um outro tipo de leitor, abre lugares de fala diferenciados para si, suas fontes e seus leitores e representa em suas páginas posições sociais e capitais simbólicos de maneira diferente.

Se é pertinente e necessário analisar criticamente os jornais populares pelo ponto de vista do habitus jornalístico, também é muito produtivo estudálos em sua movimentação em direção ao mundo do leitor, na perspectiva de 
que o discurso só alcançará seu valor e seu sentido em relação a um mercado (BOURDIEU, 1998, p. 54).

O aporte que propomos reconhece as implicações das posições sociais e simbólicas do jornal e do leitor e incorpora a noção de mercado de leitores, a partir da idéia de que para explicar o discurso, é preciso conhecer as condições de constituição do grupo no qual ele funciona (BOURDIEU. 1994, p. 163). Por isso, consideramos importante analisar a imprensa a partir da préexistência de uma topografia social sobre o jornal, suas fontes e seus leitores (MAINGUENEAU, 1989) e da imagem que esses jornais têm do leitor popular, o que leva ao extravasamento da lógica jornalística e a uma reapropriação de Modos de Endereçamento populares.

O conceito de Lugares de Fala é um instrumento teórico-metodológico que cria um ambiente explicativo para evidenciar que os jornais populares ou de referência falam de lugares diferentes e concedem espaços diversos ìs falas das fontes e dos leitores, mesmo que sejam editados pela mesma empresa. Assim, cada publicação torna visíveis determinados atores e representa o popular de mancira diversa.

Optamos por abordar o segmento popular da grande imprensa sob esse conceito para registrar a importância de estudá-lo no lugar en que ele faz sentido. Não consideramos o jornalismo um discurso único,autista e totalmente autônomo, mas evidenciamos seus aspectos plurais em sua constitutiva tensão com a lógica do mercado e suas relações com vários Modos de Endereçamento.

Consideramos, como ensina Landowski (1992), o jomal como uma verdadeira pessoa moral, uma empresa que age como coletividade dotada de personalidade jurídicà, estatuto e razão social. e, constitui-se em figura social. em marca, em sujeito semiológico, em um circuito que organiza a fala. Por isso, tratamos o Lugar de Fala do jornal como um todo, embora analiticamente pudéssemos desdobrá-lo em vários.

As estratégias discursivas de um Lugar de Fala obedecem a determinadas regras para serem autorizadas e legitimadas. Afinal, "ninguém entrará na ordem do discurso se não satisfizer a certas exigências ou se não for, de início. qualificado para fazê-lo" (FOUCAULT, 1998, p.37). Foucault (1998. p. 37) denomina de rarefação os procedimentos pelos quais as condições de funcionamento dos discursos impõem aos indivíduos certo número de regras e, assim, não permitem que todo mundo tenha acesso a eles. Atirma que os rituais da palavra, as sociedades do discurso, os grupos doutrinários e as apropriações sociais estão ligados e constituem-se em espécies de grandes edifícios que garantem a distribuição dos sujeitos que falam nos diferentes tipos de discurso e a apropriação dos discursos por certas categorias de sujeitos. Brandão (1998, p.31) baseia-se em Foucault para afinnar que o discurso é o espaço em que o saber e o poder se articulam, pois quem fala, fala de algum lugar, a partir de um direito reconhecido institucionalmente e esse discurso que veicula saber é gerador de poder. $\mathrm{O}$ 
jornal tem o poder simbólico, é um porta-voz autorizado, sua fala "concentra o capital simbólico acumulado pelo grupo que lhe conferiu o mandato e do qual ele é, por assim dizer, o procurador'. (BOURDIEU, 1998, p. 89).

Braga (2000) busca construir a noção de Lugar de Fala como conceito metodológico para estudo de produtos culturais ${ }^{72}$. Acredita que o lugar de sentido não é inteiramente pré-existente e se constrói na trama entre a situação concreta com que a fala se relaciona, a intertextualidade disponível e a própria fala como dinâmica selecionadora e atualizadora de ângulos e construtora da situação interpretada. Assim, é insuficiente buscar sentido só na estrutura formal da fala, nas inserções interdiscursivas ou nas circunstâncias do contexto, pois os Lugares de Fala transcendem o discurso.

$\mathrm{O}$ autor adota 'fala' e não texto ou discurso para associar o conceito a uma situação concreta, específica, historicamente descritível. Trata-se de um conceito nemi estritamente lingüístico, nem exclusivamente sociológico. Não diz respeito ao contexto, mas ao lugar construído pelo discurso neste contexto (BRAGA, 2000). O desenvolvimento do conceito tem o objetivo de compreender criticamente o produto, ultrapassando suas contradições e buscando perceber em que espaço (apesar e através dessas contradições) ele faz sentido. De posse deste sentido é que se faria à crítica de seu Lugar de Fala (o lugar construído pelo produto cultural para 'ver o mundo').

Braga (2000) constata que alguns dos estudos que privilegiam um produto cultural como objeto empírico, embora tenham esse produto como 106 ponto de partida para o início do estudo, rapidamente se dispersam, afastandose excessivamente ou precocemente da fala propriamente dita e 'perdendo de vista sua concretude'. Há o que ele denomina 'deslocamento de objeto', como se o objeto empírico fosse meramente uma forma de aproximação para outros objetos mais teóricos. Esses deslocamentos produzem conhecimentos relevantes, mas há uma necessidade de aproximação mais concreta com o objeto: A preocupação de Braga é que o estudo procure as especificidades da fala e evite saltar imediatamente para as grandes configurações que acabam por abstrair o âmbito prático.

Para o autor, o Lugar de Fala é uma lógica que articula fala, textos e situação. O Lugar de Fala define-se pelo cotejo com outros Lugares de Fala vizinhos. Trata-se de uma situação concreta, específica, historicamente descritível. O conceito não é reduzido ao lugar sociológico do falante, à sua posição no mundo, mas o contém, corresponde ao lugar construído pelo discurso no contexto. O que esta fala tenta construir, recortar, responder no espaço social? Toda fala tenta resolver problemas de ordem imediata. Uma fala 'produz uma resposta e o lugar em que esta resposta faz sentido'. (BRAGA, 2000, p.170). Assim, pesquisar um Lugar de Fala corresponde a 'buscar o máximo de concretude conceitualizável desssa fala - observar o tipo de situação de que ela participa e como trata de reagir a esta situação e construí-la'. (BRAGA, 2000, p. 179). 
Nessa busca de um conceito de Lugar de Fala para analisar a imprensa, circulamos por vários outros aportes teóricos. Dizem Guimarães e Orlandi, baseados em Michel Pêcheux, que 'as palavras mudam de sentido segundo as posições daqueles que as empregam' (1988). Para Orlandi, o Lugar de Fala está relacionado ao plano social porque tomar a palavra é um ato social com todas as suas implicações (conflitos. reconhecimentos, relações de poder, constituição de identidades). ou seja, o 'lugar a partir do qual fala o sujeito é constitutivo do que ele diz'. (ORLANDI, 2002, p. 39). Se o jornal fala de lugar posicionado socialmente e detentor de um poder simbólico, quando comunicarse com um público popular, pode optar por falar diferentemente do que se estivesse dirigindo-se a um público formador de opinião.

Assim, um jornal sempre destina-se a um mercado e, portanto. o discurso jornalístico só existe efetivamente em direção a um público alvo. Eo jornal tem o poder simbólico para delerminar de onde vai falar para cada público e como vai posicionar suas fontes e seus leitores em suas páginas.

Detemo-nos nas condições sociais de produção do discurso na perspectiva de Bourdieu, ou seja, nas posições ocupadas pelos agentes e instituições e naquelas destinadas ao mercado para o qual o jornal foi produzido $^{73}$. A concepção de Bourdieu de que é toda a personalidade social está presente na fala do locutor nos é central, ou seja. a razão de ser de um discurso não reside só na competência lingüística do locutor, mas no lugar social a partir do qual o discurso é proferido, nas propriedades pertinentes de uma posição (BOURDIEU, 1994, p. 167-173). pois toda a estrutura social integra a interação e o discurso. O discurso jornalístico não pode ser dissociado de suas condições sociais de produção, de reprodução e de utilização e da posição social dos seus 'interlocutores'.

Incluímos em nossa abordagem a visão antecipada do campo da recepção. As condições sociais de aceitação do discurso são essenciais para o ato de comunicação, ou seja, as condições de recepção antecipadas fazem parte das condiç̃̃es de produção do discurso. Assim, os Lugares de Fala dos jornais relacionam-se com determinados mercados, e. portanto. com a visão que os agentes sociais e instituições têm de si e do outro.

Quem fala, além de enunciar uma sentença, está envolvido em situações nas quais seu discurso possui um valor. Existe um mercado de sentidos no qual as falas desfrutam de valores diferenciados. A fala, para ser levada em consideração e ser escutada, deve ter legitimidade. Os Lugares de Fala relacionam-se intensamente com as condições de existência de um discurso que são dadas pela resposta às perguntas: Quem pode falar o quê? Para quem? Em que lugar?. (PINTO, 1989, p. 39).

Nessa perspectiva, os jornais constroem representações de si mesmos e de seus públicos por intermédio das posições sociais e dos capitais simbólicos em jogo e da visão prévia que eles têm dos seus leitores. Os Lugares de Fala, no nosso recorte, são a representação das posições sociais 
e da posse de capital simbólico dos agentes sociais envolvidos, principalmente do jornal e os leitores, que geram Modos de Endereçamento específicos.

\section{O conceito desmembrado}

Ao desmembrarmos o conceito de Lugares de Fala, podemos dizer que a idéia de Lügar nos é bastante significativa; é um espaço ocupado, um ponto de vista relacional, uma posição determinada num conjunto ou um ambiente. Falar é apropriar-se de estilos expressivos já constituídos no e pelo uso, objetivamente marcados por sua posição numa hierarquia de estilos que exprime a hierarquia dos grupos, é produzida para e pelo mercado ao qual ela deve sua existência e suas propriedades mais específicas. (BOURDIEU, 1998).

A fala é o que exprimimos com a palavra e está associąda a uma situação concreta, trata-se do discurso proveniente de um lugar. Ou seja, uma fala não pode ser analisada de forma deslocada das condições sociais de seu falante. A fala jornalística nas pụblicações populares não existe de forma isolada, é produzida especialmente para determinados mercados.

Os agentes sociais são constituídos como tais em e pela relação com um espaço social ou campos e não há espaço que não seja hierarquizado (BOURDIEU, 1997). Os Lugares de Fala são lugares constituídos e legitimados a partir de posições sociais e capitais simbóliços. Não se configuram simplẹsmente como relação de comunicação, mas como relações de poder.

108 Como lembra Ortiz (1994, p. 13), para Bourdieu, a comunicação se dá enquanto 'interação soçialmente estruturada', isto é, os agentes da 'fala' entram em comunicação num campo onde as posições sociais já se encontram objetivamente estruturadas. O ouvinte não é.o 'tu' que escuta o 'outro' como elemento complementar da interação, mas se defronta com o 'outro' numa relação de poder que reproduz a distribuição desigual de poderes agenciạdos ao nível da sociedade global.A posição social dos agentes pode ser definida pela posição que jornais e leitores ocupam nos diferentes campos, pela distância que os separa e pelo volume e estrutura de seus capitais, a partir das características da empresa que edita o jornal e do leitor a quem o jornal se dirige. Adotamos o termo agentes sociais para registrar a não passividade de um ou outro pólo no processo de comunicação.

Os capitais simbólicos de que jornal e leitor estão investidos são compreendidos como energias baseadas em relações de sentido, reconhecidas socialmente, fundadas sobre a necessidade dos homens de justificarem sua existência social. O capital simbólico não é um tipo de capital como os demais, mas relaciona-se com os efeitos simbólicos dos demais capitais. $O$ discurso supõe um emissor legítimo dirigindo-se a um destinatário também legítimo e reconhecido. (BOURDIEU, 1994, p. 161). A imprensa dispõe, além de capitais econômicos, culturais e sociais, de um capital simbólico relevante e sua posição implica uma propensão a falar determinadas coisas de determinadas 
maneiras. Já o capital simbólico do leitor levado em consideração no campo jornalístico varia de acordo com cada tipo de publicação.

A representação é entendida como a projeção ou a reprodução do que o jomal pensa sobre si mesmo e sobre o leitor. É uma retradução simbólica, trata-se do processo de colocar um conceito ideológico abstrato em formas concretas, reforça a noção de reapresentação - o refazer e o trazer à vista diferentes significados para o 'mesmo' significado. (HARTLEY, 2001, p. 214). Ou seja, a representação dos agentes sociais integra também sua constituição. A representação parte de um conceito prévio que o jornal tem do leitor. por isso, o jornal adota Modos de Endereçamento. ou seja. bases a partir das quais o jornal interpela e posiciona o leitor. O Modo de Endereçamento referese à necessidade que a imprensa tem de se conectar com o mundo do leitor $\mathrm{e}$ de estabelecer uma relação com ele. O conceito de Modos de Endereçamento provém dos estudos de cinema e foi aplicado por Ellsworth (2001) ao campo da Educação. Refere-se, no campo cinematográfico, à relação do texto de um filme com a experiência do espectador. A pergunta central é: - Quem esse filme pensa que você é?. Baseia-se no argumento que para que ofilme funcione para um determinado público, o espectador deve entrar em uma relação particular com a história. Ao abordarmos os Modos de Endereçamento de um jornal, podemos questionar como ele constrói um caminho até o seu leitor: A quem o jornal é endereçado?, Quem o jornal pensa que seu público é? e Quem esse jornal deseja que o leitor seja?. Ou seja, voluntariamente ou não, os jornais adotam Modos de Endereçamento, que posicionam o leitor popular em lugares diversos do leitor de classe média ou do leitor formador de opinião.

Os Modos de Endereçamento podem ser relacionados ao que Pêcheux (1993) denomina de Formações Imaginárias: os lugares que emissor e destinatário atribuem a si mesmo e ao outro, e a imagem que eles fazem do seu próprio lugar e do lugar do outro. Podem ser descritas como a imagem do lugar de A para o sujeito colocado em A (Quem sou eu para the falar assim?), a imagem do lugar de $B$ para o sujeito colocado em $A$ (Quem é ele para que eu lhe fale assim?), a imagem do lugar de B para o sujeito colocado em B (Quem sou eu para que ele me fale assim?) e a imagem do lugar de A para o sujeito em B (Quem é ele para que me fale assim?). (PÊCHEUX, 1993, p. 83). Segundoo autor, o sujeito é determinado pelo lugar de onde fala e todo processo discursivo supõe, por parte do emissor, uma antecipação das representações do receptor, sobre a qual se funda a estratégia do discurso.

Por antecipação, o jornal projeta um leitor e estabelece suas estratégias com base nele. Por sua vez, o leitor também projela um jornal e imagina o que a publicação deve dizer e como deve dizer. Tanto o emissor quanto o destinatário atribuem lugares a si mesmo e um ao outro e constroem imagens. de seu próprio lugar e do lugar do outro. Ou seja. o emissor antecipa as representações do receptor e com a antevisão do imaginário do outro, funda estratégias de discurso. Trata-se de uma antecipação das relaçôes de sentido 
não totalmente calculada ou planejada, mas seguidora da lógica da experiência, do que 'dá certo', e no caso da imprensa em questão, da lógica do mercado.

É evidente, entretanto, que um jornal pode adotar uma multiplicidade de formas de endereçamento simultâneas, e o leitor também está envolvido em muitas delas em suas experiências cotidianas. Além disso, os leitores podem ler os jornais a partir de outros lugares e responderem de formas diferentes daquelas esperadas. Dessa forma, não há uma coincidência total entre endereço e resposta, mas sim um espaço social formado por uma conjuntura histórica de poder e diferenças sociais e culturais, como afirma ELLSWORTH (2001, p. 47). Com base na autora (2001, p. 25), podemos afirmar que embora o público não possa ser simplesmente posicionado por um determinado Modo de Endereçamento, os jornais oferecem sedutores estímulos e recompensas para que se assumam aquelas posições de gênero, status social, raça, nacionalidade, atitude, gosto, estilo às quais um determinado produto cultural se endereça.

No segmento popular da grande imprensa, mesmo que uma única empresa possa editar um jornal de referência e um popular, a posição social e o capital simbólico tanto da publicação quanto dos leitores funcionami de uma forma diferente na construção de cada discurso, pois a imagem que o jornal tem de seu leitor faz com que outro lugar de fala seja construído. Assim, no jornalismo de referência a empresa jornalística coloca-se a falar a partir de uma determinada posição social, convoca fontes localizadas em lugares 110 privilegiados de fala e omite determinadas vozes. Em alguns jornais do segmento popular da grande imprensa, há mudanças ria concessão da palavra. Assim, se os jornais populares falam de um outro lugar para dirigirem-se ao povo, gerindo de formas diversas suas posições sociais e capitais simbólicos, nesse lugar o povo e seu universo cultural têm ampla visibilidade. O popular, normalmente interditado na imprensa de referência, ganha espaço embora seja mantido numa posição social e simbólica excludente.

Explica Ellsworth (2001, p. 47), que o Modo de Endereçamento consiste na 'diferença entre o que poderia ser dito - tudo o que é histórica e culturalmente possível e inteligível de se dizer - e o que é dito'. Partimos, então, do pressuposto que o segmento popular da grande imprensa considera seu leitor como 'popular' e parte desse imaginário para construir sua relação com ele. Dessa forma, a construção do leitor nas páginas dos jornais destinados à população de baixa renda se dá a partir de uma imagem do que deva ser um produto popular. Imagem essa que tem raízes históricas no movimento dialético entre a indústria da cultura e seu público.

As Matrizes Culturais tornadas populares ao longo da história têm subsidiado a imprensa na comunicação com esses setores, por intermédio da tematização dos dramas de reconhecimento; da mediação entre os tempos do capital e da cotidianidade, do entendimento familiar da realidade; da confluência público e privado; do desenvolvimento de solidariedades 
baseadas no local, no parentesco, na vizinhança: da noção de que política só interessa se afeta a vida diária; da ligação entre problemas sociais e dramas pessoais; e a apresentação de personagens 'em carne e osso" e assim por diante.

Decorrente dessa Matriz popular, a incorporação da fala das camadas populares é um dos caminhos amplamente utilizado por essa imprensa. A ancoragem, efeito de atar o discurso a pessoas que o leitor reconhece como existentes, é uma das estratégias para chamar a atenção do leitor popular. As falas num jornal estão ligadas à complexa rede de interesses que existem na atividade jornalística. Quem fala num jornal, fala a partir de relações objetivas de dominação, subordinação, complementaridade ou antagonismo. ou seja, fala a partir de posições sociais diferentes, que detêm ou não os diversos capitais. Ao campo jornalístico corresponde um mercado simbólico de igual vigor ao de bens materiais, em que os agentes não competem em igualdade de condições. E o poder em jogo é o simbólico, que determina quem tem acesso à visibilidade ou não. O campo jornalístico é regido por determinadas regras que moldam o que é legítimo ser falado e ocorrem muitas disputas no interior do campo em função da variação de posição dos agentes na aceitação, ou não, das demandas mercadológicas. As empresas jornalísticas e os agentes sociais que falam no jornal negociam. entram em confronto. e estabelecem alianças cotidianamente para impor seus modos de percepção. classificação e intervenção na sociedade. ou seja, ambicionam o poder simbólico, o poder de construir a realidade e definir o mundo social.

\section{O leitor do mundo e o mundo do leitor}

O conceito de Lugares de Fala é pertinente ao estudo dos jornais auto-intitulados populares porque registra a importância de estudar a fala no seu lugar. Se o jornalismo de referência fala do lugar de 'leitor do mundo", o segmento popular fala do lugar 'do mundo do leitor'. Assim. o fato de ser dirigido a populares é constitutivo do que os jornais desse segmento dizem. $O$ recurso dos Lugares de Fala traz aportes importantes por considerar a movimentação da empresa jornalística em relação a seu público alvo. O segmento popular da grande imprensa fala de um lugar social e simbólico diferente para que sua fala faça sentido. Prevê condições de recepção diversas das dos jornais de referência. Os agentes sociais (jornal. fontes e leitores) envolvidos estão em outras posições das verificadas nos jornais tradicionais e embora o lugar social da empresa que mantém o jornal possa ser o mesmo lugar de edição de um jornal de referência, a posição social e o capital simbóiico do jornal são re-configurados.

A imprensa de referência representa-se como quem explica o mundo a um cidadão interessado em compreendê-lo e os lugares disponíveis para as falas do leitor e das fontes relacionam-se ao volume de capital social. 
econômico e cultural dos agentes. Nos jornais populares, a estratégia muda. Os jornais utilizam-se de forma diferente de seu poder simbólico (o 'fazer sentir' no lugar do 'fazer saber'). A expropriação econômica e cultural dọ leitor torna-se capital simbólico (a necessidade como virtude) e o jornal fala do mundo das horizontalidades porque os fatos públicos supostamente não interessam aos seus leitores.

O jornal que pesquisamos, o Diário Gaúcho, surgiu destinado a um público que não costumava ler jornal, a um 'lumpezinato da informaçạ̃o', conforme as palavras do editor-chefe do DG em 2001, Cyro Silveira Martins Filho. Por isso, 'é barato, útil, fácil de ler, emocionante, sem ser apelativo, e aborda o cotidiano desse público':

[...] é um jornal que conquistou a simpatia de crianças, jovens, adultos e avozinhos. Como não seria simpático um jornal que ajuda a conseguir emprego? A economizar? A comprar? A ganhar um dinheirinho extra? A se defender da violência cotidiana? A se divertir? A exigir direitos fundamentais,esquecidos ou desconhecidos? Que ajuda a prevenirse das doenças. Que orienta na obtenção de auxílio ou socorro? Que está do lado da vida e não admite a banalização da morte? Que defende seus leitores quando ninguém ou instituição alguma está disposto a fazê-lo? Que entende a dor alheia? Que vigia o poder público? No qual pessoas que só seriam notícia em situação de vítimas ou de humillhação são protagonistas de histórias edificantes? (MARTINS FILHO, 2003, on-line).

O jornal em questão, assim como outros produtos jornalísticos populares representa-se como tendo interlocução com os poderes instituídos, como prestador de serviço e promotor de assistencialismo, como veículo que fala 'a língua' do leitor e.concede a ele o status de fonte. Ilustra o mundo popular sem a pretensão de explicá-lo, a partir da singularização dos fatos, da dramatização no lugar do conhecimento e da adoção de características populares. Considera que a política só é interessante quando afeta a vida diạ́ria, aborda situações de exclusão social, mas aponta para soluções individuais e locais e veicula um entendimento familiar da realidade. $O$ públicu e o privado misturam-se e há uma tênue divisão entre informação e entretenimento. O leitor é representado como alguém sem interlocução com o poder, necessitado de assistencialismo e prestação de serviço, fascinado com a visibilidade de seu mundo privado e desinteressado na explicạção de fatos de interesse público. 


\section{Para finalizar}

Se rompermos com o conceito de sensacionalismo, onde tudo cabe e pouco se explica, será possível aparar especificidades do segmento popular da grande imprensa de uma forma mais precisa. O conceito de Lugar de Fala tem esse propósito. Mostrar que a característica básica dos produtos jornalísticos populares é o fato de eles falarem de um lugar diferente, de haver uma mudança na concessão da palavra, na representação do popular, no enquadramento das notícias e nos valoresnotícia - estratégias que transcendem em muito a idéia do sensacionalismo.

\section{Referências Bibliográficas}

BOURDIEU, Pierre. A Economia das Trocas Lingüísticas. In: ORTIZ, Renato (org.). Pierre Bourdieu. São Paulo: Ática, São Paulo, 1994. p. 156183. Coleção Grandes Cientistas Sociais, n. 39.

As Regras da Arte. São Paulo: Companhia das Letras, 1996. . Efeitos de Lugar. In: BOURDIEU, Pierre (org). A Miséria do

Mundo. Petrópolis, RJ: Vozes, 1997. p 159-166

A Economia das Trocas Lingüísticas: O que falar quer dizer. 2. ed. São Paulo: Editora da Universidade de São Paulo, 1998.

BRAGA. José Luiz. Comunicação e sociabilidade: lugar de fala. Geraes -

Revista de Comunicação Social, n. 47, jun. 1995. Belo Horizonte:

Departamento de Comunicação Social da UFMG, p. 3 a 10.

'Lugar de Fala' como conceito metodológico no estudo de produtos culturais. In: MALDONADO, Alberto Efendy: FAUSTO NETO, Antonio; COGO, Denise; BRAGA. José Luiz et alli. Mídia e processos socioculturais. São Leopoldo: Programa de Pós-Graduação em Comunicação da Universidade do Vale do Rio dos Sinos, 2000. p. 159-184. BRANDÃO, Helena Nagamini. Introdução à Análise do Discurso. 7. ed. Campinas, SP: Unicamp, 1998.

ELLSWORTH, Elisabeth. Modo de Endereçamento: uma coisa de cinema: uma coisa de educação também. In: SILVA, Tomaz Tadeu da (org). Nunca Fomos Humanos: nos rastros do sujeito. Belo Horizonte: Autêntica, 2001. p. 07-76.

FOUCAULT, Michel. A Ordem do Discurso. 4. ed. São Paulo: Loyola, 1998. GINER Juan. Los Nuevos diários populares de calidad. Disponible em: <http: www.innovacion.com/innovation cast/ cast diariospopulcalidad.htm. Acesso em: $07 \mathrm{fev} .2004$.

HARTLEY, John. Representação. In: O'SULLIVAN. Tim et alii. Conceitoschave em estudos de comunicação e cultura. Piracicaba: UNIMEP, 2001 p. 214. 
LANDOWSKI, Eric. A Sociedade Refletida. São Paulo: Pontes, 1992. MAINGUENEAU, Dominique. Novas Tendências em Análise do Discurso. Campinas, SP: Editora da Unicamp, 1989.

MARTINS FILHO, Cyro Silveira. Cyro Silveira Martins Filho: entrevista [jul. 2001]. Entrevistador: Flávio Porcello. Porto Alegre: TV PUC, Programa Argumentos, 2001. [1 VHS].

MARTINS FILHO, Cyro Silveira. Páginas de sangue no Diário Gaúcho.

Revista Press. Disponível em: <http://www.revistapress.com.br/press2003/ especial26.asp >. Acesso em: 15 abr. 2003.

ORLANDI, Eni. Análise de Discurso: Princípios e procedimentos. 4. ed.

Campinas, SP: Pontes, 2002.

ORTIZ, Renato. A procura de uma sociologia da prática. In: ORTIZ, Renato (org). Pierre Bourdieu. São Paulo: Ática, 1994. p. 7-37.

PÊCHEUX Gadet,F; HAK, T. (org.). Análise Automática do Discurso. 2. ed. Campinas: Editora da UNICAMP,1993.

PINTO, Celi. Com a Palavra o Senhor Presidente José Sarney. São Paulo: Hucitec, 1989.

\section{Notas}

${ }^{1}$ Braga baseia-se fundamentalmente em Michail Bakhtin, Lucien Goldmann e 114 Jean Faye para mostrar a relevância dà realidade efetiva nas condições reais de comunicação. Propõe uma análise dos enunciados na sua concretude e mostra que a situação social é constitutiva da fala.

${ }^{2}$ Não entendemos que a análise do discurso deva ser reduzida às condições sociais de sua produção e à posição do produtor no campo de produção, apenas optamos por este recorte analítico. 